\title{
THE EFFECTS OF TEST SET-UP ON THE APPARENT FLEXURAL MODULUS OF THIN ANGLE-PLY LAMINATES USING STANDARD FOUR-POINT BEND TESTING
}

\author{
D. WOWK ${ }^{1} \&$ C. MARSDEN ${ }^{2}$ \\ ${ }^{1}$ The Royal Military College of Canada, Canada. \\ ${ }^{2}$ Concordia University, Canada.
}

\begin{abstract}
Four-point bending is a standard test method that can be used to determine flexural properties of a material or for quality control. The ASTM and ISO test standards specify an allowable range of set-up parameters such as the coupon width, the support span and the load span that can be used to determine the flexural modulus. When angle-ply laminates are tested in four-point bending the apparent flexural modulus is over predicted due to the bending-twisting coupling and the interaction between the coupon and the test fixture. In the present study, the effect of the test configuration on the apparent flexural modulus of thin angle-ply laminates in four-point bending is evaluated for six different layups. It is shown that test set-ups that allow more twisting of the coupon will result in apparent flexural moduli that are closer to the theoretical value. The torsional moments induced by the test fixture are quantified, and it is shown that they are directly responsible for the increase in the apparent flexural modulus. Keywords: angle-ply laminates, bending-twisting coupling, finite element analysis, flexural modulus, four-point bending, induced torsion.
\end{abstract}

\section{INTRODUCTION}

Coupon testing of materials is often performed to determine material properties such as the in-plane and shear modulus of elasticity and the stress and strain at failure. These properties can be used in subsequent analysis in order to evaluate and compare designs in terms of strength or stiffness. Coupon testing may also be performed for quality control and to develop metrics on the expected variation in material properties. When performing coupon tests for composite laminates, bending tests are often preferred over tensile tests as the specimen geometry is much simpler and smaller, less load is required to induce failure and the tension side of the coupon can help stabilize the compressive side to avoid premature failure in buckling. One difficulty in interpreting flexural test results for composite laminates is that the stacking sequence affects the overall bending behaviour, and properties of the individual lamina are not easily determined. For example, the flexural modulus of a composite laminate is not equal to the tensile modulus as is the case with homogenous, isotropic materials. In addition, the stress at failure must be calculated using methods such as the laminated beam theory and assumptions as to the applied loading and stress state must be made. The challenge with composite materials is to determine how coupon tests can be used to determine properties that can be used for design and analysis, rather than strictly for quality control.

ASTM standards D7264 and D6272, and ISO standard 14125 [1-3] describe the test procedure for four-point bending of composite materials. Within these standards, a range of load spans, support spans and widths are allowed. Support spans may be between 16:1 and 60:1 (ratio of support span to thickness) and longer spans are required to reduce the influence of shear deformation in highly anisotropic composites. Widths between $13 \mathrm{~mm}$ and $80 \mathrm{~mm}$ are recommended depending on the material type and thickness, and the load span can either be $1 / 3$ or $1 / 2$ of the support span. These standards also provide the equations to calculate properties such as the flexural modulus and the maximum flexural stress and strain. It has been 
noted, however, that the apparent flexural modulus calculated using these tests is higher than the actual laminate modulus due to the effects of shear coupling [4].

The flexural modulus for composite materials determined using bending tests has been examined by Whitney et al. [5] and Lopez-Anido et al. [6] who found that the apparent flexural modulus varies with the gauge length to width ratio of the coupon. It was also noted that the shear coupling term $\delta_{16}$ in the laminate compliance matrix causes the coupon to twist about its longitudinal axis [5]. Grédiac [7] performed experimental and numerical four-point bend tests on off-axis composites and determined that the conventional test set-up is not able to measure bending compliances due to the constraint that the test fixture places on the coupons. Additional torsional moments are imposed by the supports, and a fixture with rotating supports was recommended to accommodate the twisting of the coupon. In traditional bend fixtures, these torsional moments make it difficult to determine the stress states for angle-ply laminates in flexure and as a result much of the research performed using bending tests focuses on cross-ply laminates [8,9].

More recent work has focused on developing methods for using bend tests to determine composite material properties. Jalali and Taheri [10] present a method for determining the longitudinal and shear moduli for $0^{\circ}$ unidirectional laminates by a series of bend tests that vary the span to thickness ratio. Vargas and Mujika $[11,12]$ have focused on the use of three-point bend tests for determining the in-plane shear properties for composite laminates. Lift-off between the test coupon and the test fixture supports needed to be accounted for and analytical approaches for determining the displacement field and the lift-off condition for off-axis composites in three-point flexure have been determined [13-15]. The importance of predicting specimen lift-off for determining composite material properties has led to finite element analysis being used to simulate the displacement and stress fields of angle-ply laminates in three-point flexure for a single laminate ply [16]. While results from finite element simulations of cross-ply laminates in three-point bending [17] and four-point bending [18] have been published, simulations involving multi-directional laminate configurations experiencing bending-twisting coupling have not been performed.

In the present work, finite element simulation is used to evaluate the effects of test set-up on the apparent flexural modulus calculated using standard four-point bend tests. The specimen geometry, load span and support span are varied within the acceptable limits as stated by the ASTM and ISO standards [1-3] for six different layups. In order to predict the changing load distribution between the coupon and the test fixture that result from different amounts of shear coupling and induced twisting moments, the simulations incorporate detailed contact definitions. The extent of the lift-off, the non-uniform load distribution along the support and loading rollers, and the increase in the contact region as the span length increases are all captured. The apparent flexural modulus is compared to the theoretical modulus and to the magnitude of the twisting moment induced by the test fixture. This work represents the first stage in a longer term goal of determining how four-point bend tests in combination with finite element analysis could be used to generate material properties such as the longitudinal modulus for multi-directional laminate configurations.

\section{METHODOLOGY}

\subsection{Virtual test matrix}

Finite element simulation was used to determine the effects of the coupon width, support span and load span on the calculated flexural modulus for six different layups loaded in 
four-point bending. A $\left[0_{16}\right]$ unidirectional laminate, three angle-ply layups of the form $\left[\theta_{4} /-\theta_{4}\right]_{\mathrm{s}},\left(\theta=10,20,30^{\circ}\right)$ and two quasi-isotropic layups $\left(\left[0_{2} / 45_{2} / 90_{2} /-45_{2}\right]_{\mathrm{s}}\right.$ and $\left[45_{2} / 90_{2} /-\right.$ $\left.45_{2} / 0_{2}\right]_{\mathrm{s}}$ were considered. The coupon width was varied between $8 \mathrm{~mm}$ and $50 \mathrm{~mm}$, and two load spans of $1 / 2$ and $1 / 3$ of the support span length were tested. Support spans were varied between 16:1 and 100:1 and represent the ratio between the support span and the coupon thickness. Table 1 lists the test matrix used for the simulations with the baseline case indicated in bold.

Physical tests were also performed for the $\left[20_{4} /-20_{4}\right]_{\mathrm{s}}$ layup with a support span of $40: 1$, a load span of $1 / 2$ and widths of $8,16,24,32$ and $50 \mathrm{~mm}$ in order to validate the finite element simulations.

\subsection{Coupon specifications}

All coupons had a thickness of $2.36 \mathrm{~mm}$ and were composed of 16 plies. The coupon extended past the supports by $10 \mathrm{~mm}$ on each end resulting in a total coupon length of $114.4 \mathrm{~mm}$ for the 40:1 support span. The material was assumed to be a generic carbon epoxy with the properties shown in Table 2.

\subsection{Finite element models}

The finite element simulations were performed using the commercial software ANSYS. Each of the 16 plies was explicitly represented using higher order solid elements as shown in Fig. 1 and the orientation of each ply was defined using a local coordinate system. The rollers were represented by solid cylinders with a radius of $2.5 \mathrm{~mm}$ and were assumed to be made of steel with isotropic material properties of $\mathrm{E}=200 \mathrm{GPa}$ and $v=0.3$. The rollers were not able to rotate in the simulation, rather the coupon was allowed to slide over them with

Table 1: Test matrix used for finite element simulations

\begin{tabular}{llll}
\hline Layup & Width $(\mathbf{m m})$ & Support Span & Load Span \\
\hline$\left[0_{16}\right]$ & 8 & $16: 1$ & $1 / 3$ \\
{$\left[10_{4} /-10_{4}\right]_{\mathrm{s}}$} & $\mathbf{1 2 . 7}$ & $20: 1$ & $\mathbf{1 / 2}$ \\
{$\left[20_{4} /-20_{4}\right]_{\mathrm{s}}$} & 16 & $32: 1$ & \\
{$\left[30_{4} /-30_{4}\right]_{\mathrm{s}}$} & 24 & $\mathbf{4 0 : 1}$ & \\
{$\left[0_{2} / 45_{2} / 90_{2} /-45_{2}\right]_{\mathrm{s}}$} & 32 & $60: 1$ & \\
{$\left[45_{2} / 90_{2} /-45_{2} / 0_{2}\right]_{\mathrm{s}}$} & 50 & $100: 1$ & \\
\hline
\end{tabular}

Table 2. Orthotropic lamina material properties used in the finite element simulations

\begin{tabular}{ll}
\hline $\mathrm{E}_{11}$ & $150 \mathrm{GPa}$ \\
$\mathrm{E}_{22}=\mathrm{E}_{33}$ & $8 \mathrm{GPa}$ \\
$\mathrm{G}_{12}=\mathrm{G}_{23}=\mathrm{G}_{13}$ & $4 \mathrm{Gpa}$ \\
$v_{12}$ & 0.25 \\
$v_{23}$ & 0.46 \\
$v_{13}$ & 0.3 \\
\hline
\end{tabular}



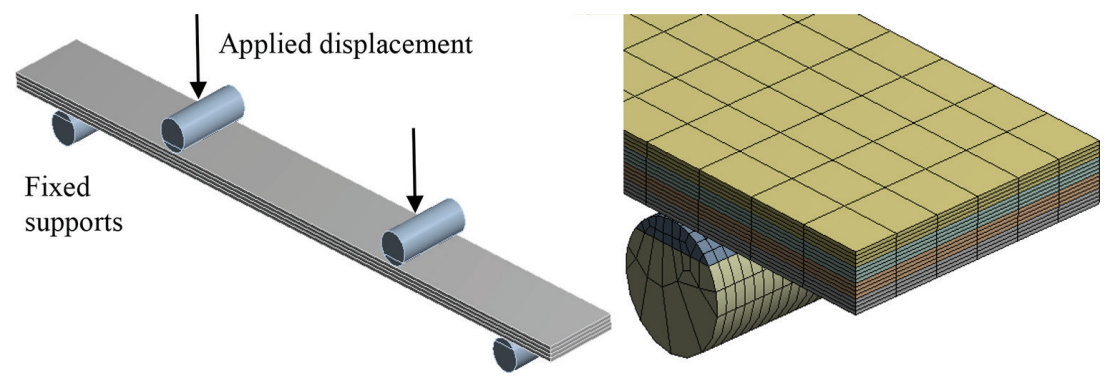

Figure 1: Simulated test set-up showing the applied boundary conditions (1/2 load span), loading and the element mesh.

a coefficient of friction of 0.2. This was intended to represent the physical test configuration (used for the physical tests in Section 3.3) which had rollers that were slightly binding. The lower rollers were fixed in all directions and a vertical displacement of $0.72 \mathrm{~mm}$ was applied to the two upper rollers which were constrained to remain horizontal. The magnitude of the vertical displacement was chosen to allow contact to fully develop between the rollers and the coupon, while still maintaining small deflections and a linear force-displacement relationship. Frictional contact elements were defined between the surfaces of the rollers and the coupon. These elements allowed for the surfaces to come in and out of contact, and to transfer loads according to the non-uniform pressure distribution between the surfaces.

\subsection{Calculation of the flexural modulus}

The flexural modulus of the coupon was determined using eqns (1) and (2), where $L$ is the support span, $t$ is the thickness of the coupon, $b$ is the coupon width, and $m$ is the slope of the force-displacement curve [1]. The displacement was extracted at the lower surface of the coupon, at the centre of the gauge region where the LVDT would be positioned in a physical test. The force was extracted from the reactions at the supports.

For a load span of $1 / 2$ :

$$
\mathrm{E}_{\mathrm{b}(\mathrm{test})}=\frac{0.17 \mathrm{~L}^{3} \mathrm{~m}}{\mathrm{bt}^{3}}
$$

For a load span of 1/3:

$$
\mathrm{E}_{\mathrm{b}(\text { test })}=\frac{0.21 \mathrm{~L}^{3} \mathrm{~m}}{\mathrm{bt}^{3}}
$$

The theoretical modulus was determined using the $\delta_{11}$ term from the laminate compliance matrix as given in eqn (3). Lopez-Anido et al. showed that this equation for the theoretical flexural modulus accurately represents the results of experimental tests for $\mathrm{L} / \mathrm{b}$ ratios greater than $6[6]$.

$$
\mathrm{E}_{\mathrm{b}(\text { theo })}=\frac{12}{\delta_{11} \mathrm{t}^{3}}
$$




\section{RESULTS}

\subsection{General behaviour}

Figure 2 shows the deformed shape typical of all layups, where the overhanging ends displace upwards and the coupon displaces downwards between the supports. The angle ply coupons tend to twist about their longitudinal axis as indicated by the contour lines near the end of the coupon being skewed with respect to the short edges. One side of the coupon lifts off the roller, while the other side remains in contact. A saddle shape is produced between the two loading rollers where the centre of the coupon displaces less than the sides. This is indicated by the curved contour lines between the loading rollers.

The non-uniform contact between the support rollers and the coupon can be seen in Fig. 3, where red indicates regions of higher contact pressure and blue represents regions without contact. In general, the contact pressure is highest near the end of the roller where contact occurs and is zero at the other end of the roller where lift-off occurs. Figure 3 a shows the extent of the contact region for a $12.7 \mathrm{~mm}$ wide coupon compared to the $50 \mathrm{~mm}$ wide coupon shown in Fig. 3b. Wider coupons maintain contact over a longer region than the narrower coupons.

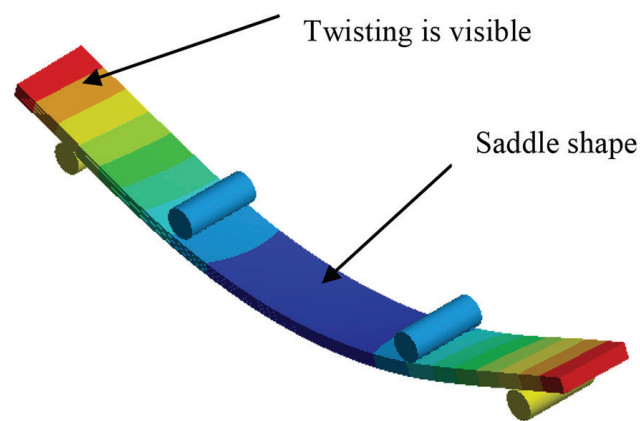

a)

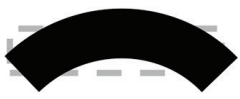

b)

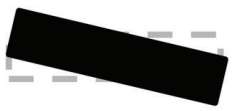

c)

Figure 2: a) Deformed shape of the coupon where red and orange indicate upwards deflections and blue indicates downwards deflection. b) Saddle-shaped deformation in the gauge region. c) Twisting between the loading rollers and the ends of the coupon. The deflection has been magnified in all these figures.

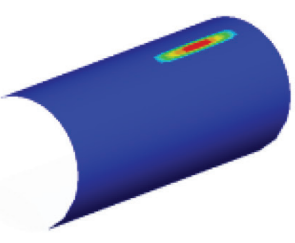

a)

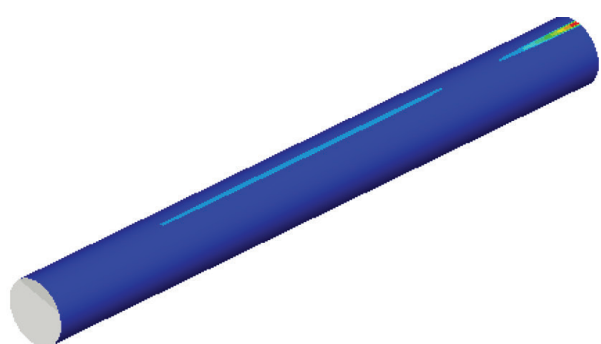

b)

Figure 3: Distribution of contact pressure on the lower rollers for the baseline case ([20/4/-20 $]_{\mathrm{s}}$ for a) $12.7 \mathrm{~mm}$ wide coupon and b) $50 \mathrm{~mm}$ wide coupon. 
The apparent flexural modulus $\left(\mathrm{E}_{\mathrm{btest}}\right)$ for the baseline test configuration was calculated from the force-displacement results of the finite element simulations using eqn (1) and are compared with the theoretical flexural modulus $\left(\mathrm{E}_{\mathrm{btheo}}\right)$ determined using eqn (3) as shown in Table 3. All the angle ply laminates had apparent flexural moduli that were calculated to be higher than their corresponding theoretical values, with the maximum difference being $34.4 \%$ for the $\left[20_{4} /-20_{4}\right]_{s}$ layup. This shows the effect of the bending-twisting coupling that occurs with angle-ply laminates. The test fixture restricts the twist of the coupon, thus reducing the displacement at the centre of the coupon and resulting in stiffer bending behaviour. The $\left[0_{16}\right]$ layup showed the two values of the flexural modulus to be within $0.5 \%$ of each other as expected due to the absence of a shear-coupling term in the compliance matrix.

\subsection{Effect of test set-up}

Increasing the width of the angle-ply coupons results in an increase in the apparent flexural modulus as illustrated in Fig. 4. The apparent flexural modulus has been normalized to the

Table 3: Comparison between the apparent flexural modulus calculated from the finite element simulations and the theoretical flexural modulus for the baseline test configuration.

\begin{tabular}{llll}
\hline Layup & $\begin{array}{l}\text { Apparent flexural } \\
\text { modulus }\left(\mathrm{E}_{\mathrm{btest}}-\mathrm{Mpa}\right)\end{array}$ & $\begin{array}{l}\text { Theoretical flexural } \\
\text { modulus }\left(\mathrm{E}_{\mathrm{btheo}}-\mathrm{MPa}\right)\end{array}$ & \% difference \\
\hline$\left[0_{16}\right]$ & 149,202 & 150,000 & -0.5 \\
{$\left[10_{4} /-10_{4}\right]_{\mathrm{s}}$} & 129,481 & 101,884 & 27.1 \\
{$\left[20_{4} /-20_{4}\right]_{\mathrm{s}}$} & 82,736 & 61,547 & 34.4 \\
{$\left[30_{4} /-30_{4}\right]_{\mathrm{s}}$} & 40,017 & 33,602 & 19.1 \\
{$\left[0_{2} / 45_{2} / 90_{2} /-45_{2}\right]_{\mathrm{s}}$} & 95,735 & 93,767 & 2.1 \\
{$\left[45_{2} / 90_{2} /-45_{2} / 0_{2}\right]_{\mathrm{s}}$} & 23,256 & 21,589 & 7.7 \\
\hline
\end{tabular}

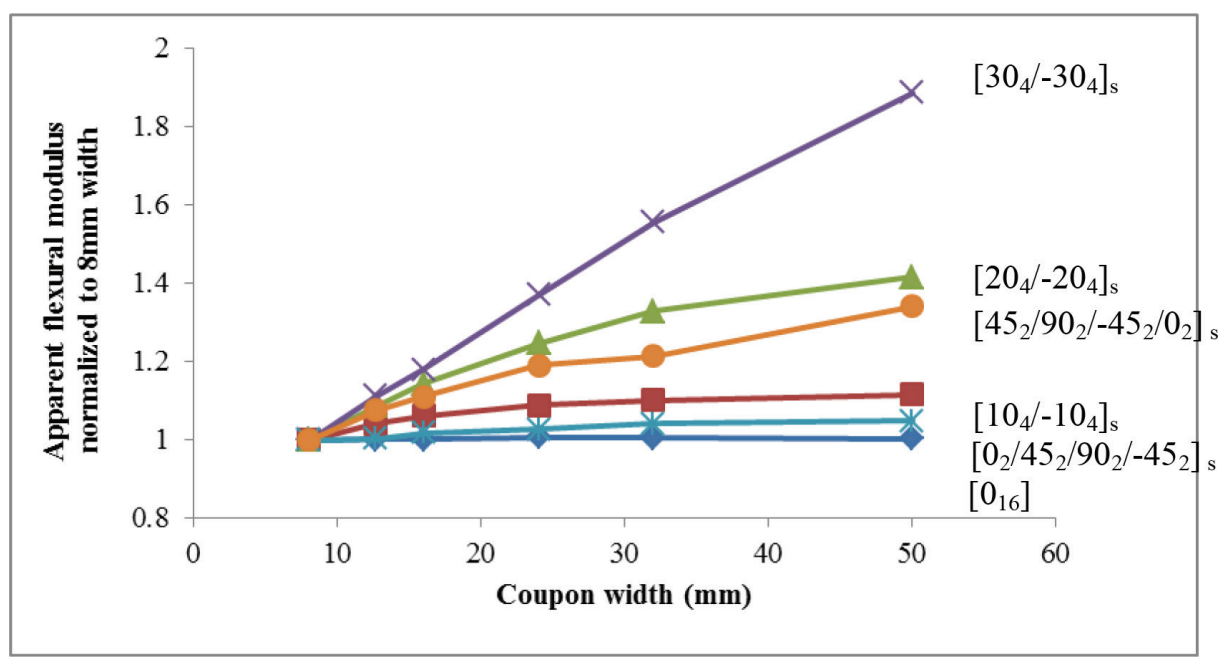

Figure 4: Apparent flexural modulus versus coupon width for a support span of 40:1 and a load span of 1/2. Results for the six different layups are shown. 
value of the $8 \mathrm{~mm}$ wide coupon in order to highlight the increase in the apparent stiffness with increasing width. The $\left[30_{4} /-30_{4}\right]_{\mathrm{s}}$ layup sees the largest increase of $88.4 \%$ between the $8 \mathrm{~mm}$ and $50 \mathrm{~mm}$ wide coupons. The $\left[0_{2} / 45_{2} / 90_{2} /-45_{2}\right]_{\mathrm{s}}$ layup showed the smallest increase of the angle ply layups at $4.9 \%$.

The apparent flexural modulus is higher for angle-ply laminates when a shorter support span is used as shown in Fig. 5. The apparent flexural modulus has been normalized with respect to the theoretical modulus and will have a value of 1 if both moduli are equal. The apparent flexural moduli for the $\left[20_{4} /-20_{4}\right]_{\mathrm{s}},\left[30_{4} /-30_{4}\right]_{\mathrm{s}}$ and $\left[45_{2} / 90_{2} /-45_{2} / 0_{2}\right]_{\mathrm{s}}$ layups tend towards the theoretical modulus as the support span becomes longer. At support spans of less than 32:1 shear effects may be present as indicated by the discontinuities of the curves. A maximum increase of $46.3 \%$ in the apparent flexural modulus occurred for the $\left[30_{4} /-30_{4}\right]_{\mathrm{s}}$ layup between spans of 100:1 and 16:1.

Equation (2) was used to calculate the apparent flexural modulus for load spans of 1/3. Changing the load span had a much smaller effect on the apparent flexural modulus as shown in Fig. 6, when compared to changing the support span. For all the layups considered here, a maximum difference of $5 \%$ between the two load spans was seen. The 1/2 span always produced larger values of $\mathrm{E}_{\text {btest }}$ because the support and loading rollers are closer together thus causing more restraint by the fixture.

In all cases, the more the test fixture is able to prevent the coupon from twisting, the more the apparent flexural modulus will increase. Less twisting results in lower bending displacements and higher apparent flexural moduli. The test fixture is more effective in resisting the twisting of the coupon when wider coupons are used because of the larger contact region. The test fixture is also more effective in resisting the twisting of the coupon when the distance between rollers is smaller.

\subsection{Experimental validation}

One panel of the $\left[20_{4} /-20_{4}\right]_{s}$ layup was fabricated from a carbon epoxy prepreg and then cut into five coupons with widths of $8,16,24,32$ and $50 \mathrm{~mm}$. Tensile tests determined that the

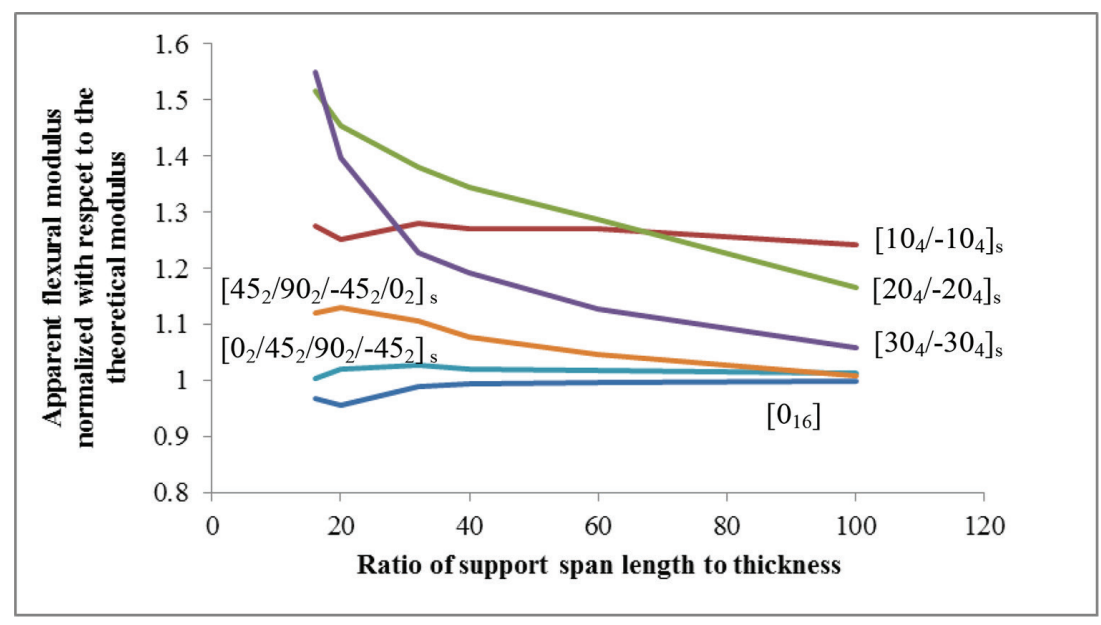

Figure 5: Apparent flexural modulus versus support span for a width of $12.7 \mathrm{~mm}$ and a load span of $1 / 2$. Results for the six different layups are shown. 


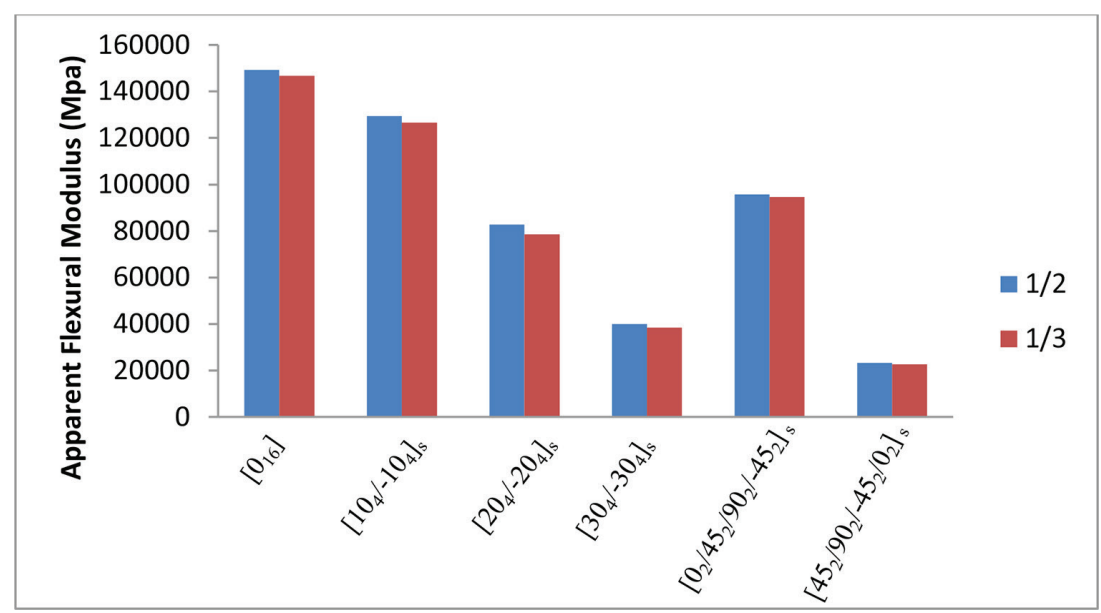

Figure 6: Apparent flexural modulus for load spans of $1 / 2$ and 1/3. Results for the six different layups are shown. All coupons had a width of $12.7 \mathrm{~mm}$ and a support span of 40:1.

longitudinal modulus of the material was $124.7 \mathrm{GPa}$. The measured dimensions of the coupons are given in Table 4 where the width and thickness were averaged at three locations along the length of each coupon.

The coupons were tested in a four-point bend fixture using a support span of 40:1 and a load span of $1 / 2$. Loads were applied to the coupons in order to produce maximum displacements at the centre of the coupon on the order of $1.5 \mathrm{~mm}$. This provided deflection is large enough to allow the coupon to settle into the fixture and produces a linear force-displacement relationship. An LVDT was used to monitor the displacement at the lower surface of the coupon at the centre of the gauge region. The slope of the resulting force-displacement curve was used in eqn (1) to obtain the apparent flexural modulus.

The finite element simulations were rerun using the geometry specified in Table 4. The material properties presented in Table 2 were used with the exception of $\mathrm{E}_{11}$ which was replaced with the measured value of $124.7 \mathrm{GPa}$.

Figure 7 shows that the apparent flexural modulus calculated from the physical and virtual test data both increase with increasing coupon width. The values of the apparent flexural modulus determined from the simulations and physical test are within 5\% of each other for coupon widths between 16 and $50 \mathrm{~mm}$ and within $15 \%$ for the $8 \mathrm{~mm}$ wide coupon. Additional physical testing on other layups showed that $8 \mathrm{~mm}$ wide coupons consistently produced

Table 4: Dimensions of coupons used for physical testing

\begin{tabular}{ll}
\hline Width $(\mathrm{mm})$ & Thickness $(\mathrm{mm})$ \\
\hline 7.74 & 2.210 \\
16.22 & 2.230 \\
24.20 & 2.375 \\
32.20 & 2.525 \\
50.10 & 2.415 \\
\hline
\end{tabular}




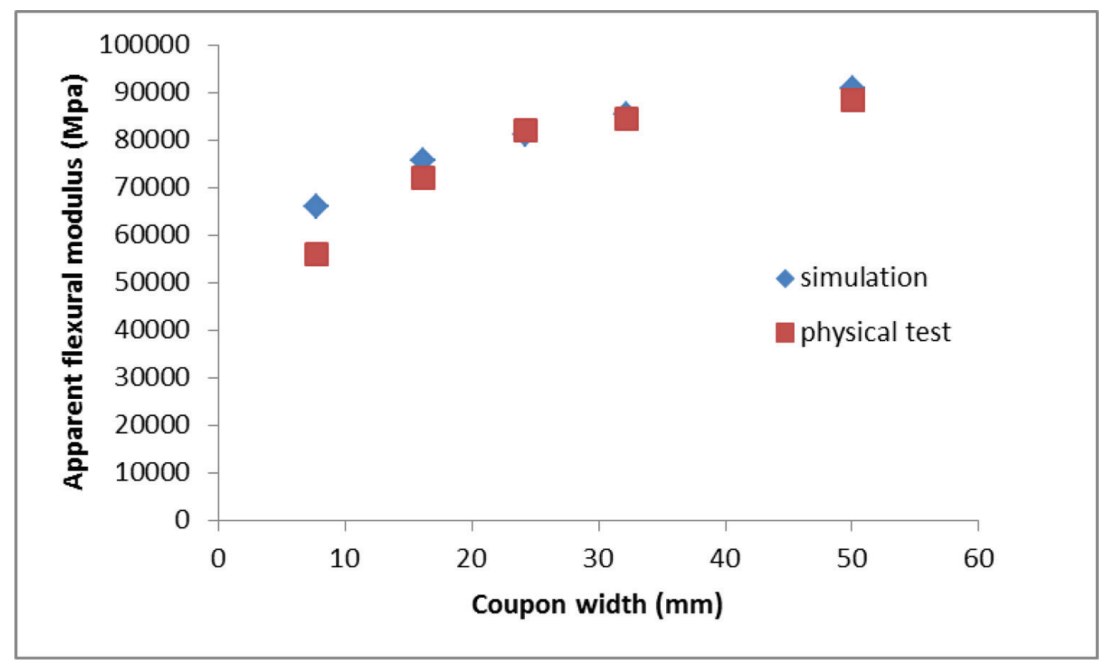

Figure 7: A comparison between the apparent flexural modulus calculated from physical test and finite element simulations. The $\left[20_{4} /-20_{4}\right]_{\mathrm{s}}$ layup was used along with the baseline test set-up.

lower apparent flexural moduli than the simulations. This is thought to be because of the initial distortion that occurs with such narrow coupons and the fact that any imperfections will have more of an influence on the stiffness for narrower coupons. More physical testing is required in order to fully validate the finite element models, but these results indicate that the finite element simulations are able to capture the interaction between the coupon and the test fixture required to predict the flexural modulus.

\section{DISCUSSION}

The results from the finite element simulations show that the configuration of the test set-up has a large effect on the calculated apparent flexural modulus, of the laminate. For the cases considered here, the four-point bend test over predicted the flexural modulus by up to a factor of 2 when compared with the theoretical value. This indicates that the flexural modulus calculated using the equations in the ASTM and ISO is not representative of a material property as it changes with different test configurations. The apparent flexural modulus is specific to each layup, coupon dimension and test configuration. This means that in its current form, it is not particularly useful in the design of full size components.

The inset in Fig. 8 illustrates how an unconstrained angle-ply coupon twists when subjected to a pure bending moment. The apparent flexural modulus calculated for this unconstrained case agrees with the theoretical modulus as shown in Fig. 8. This is why rotating constraints have been suggested as a method for measuring the flexural modulus [7]. Two disadvantages of using rotating supports are that the apparatus is more complex than traditional four-point fixtures and it does not create realistic stress states that would be seen in the field. The comparison in Fig. 8 confirms that it is the restraint provided by the test fixture that increases the apparent flexural modulus.

The horizontal rollers in the test fixture twist the coupon back to a neutral position by applying torsional moments, and it is the presence of these moments and the change in the stress state that cause the increase in the apparent flexural stiffness. Equations (1) and (2) are 


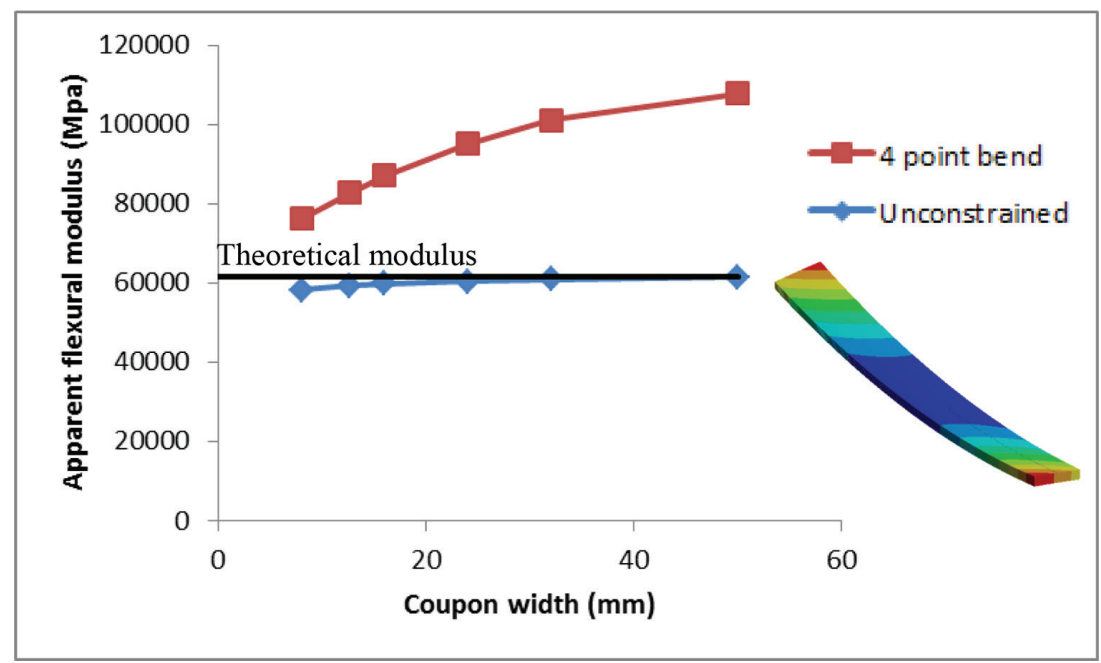

Figure 8: Comparison between the apparent flexural modulus when the coupon is loaded in four-point bending and when an unconstrained coupon is loaded with a pure moment.

both based on the assumption that the coupon is only subjected to a bending moment, and they do not account for the presence of torsional moments. To determine what effect these additional moments have on the apparent flexural modulus, the torsional reactions at the rollers were extracted and then summed to determine the torque that is present within the gauge region of the coupon. The total torque in the gauge region $(\mathrm{T})$ was then divided by the bending moment in the gauge region (M) to produce the ratio T/M. Figure 9 shows that for the

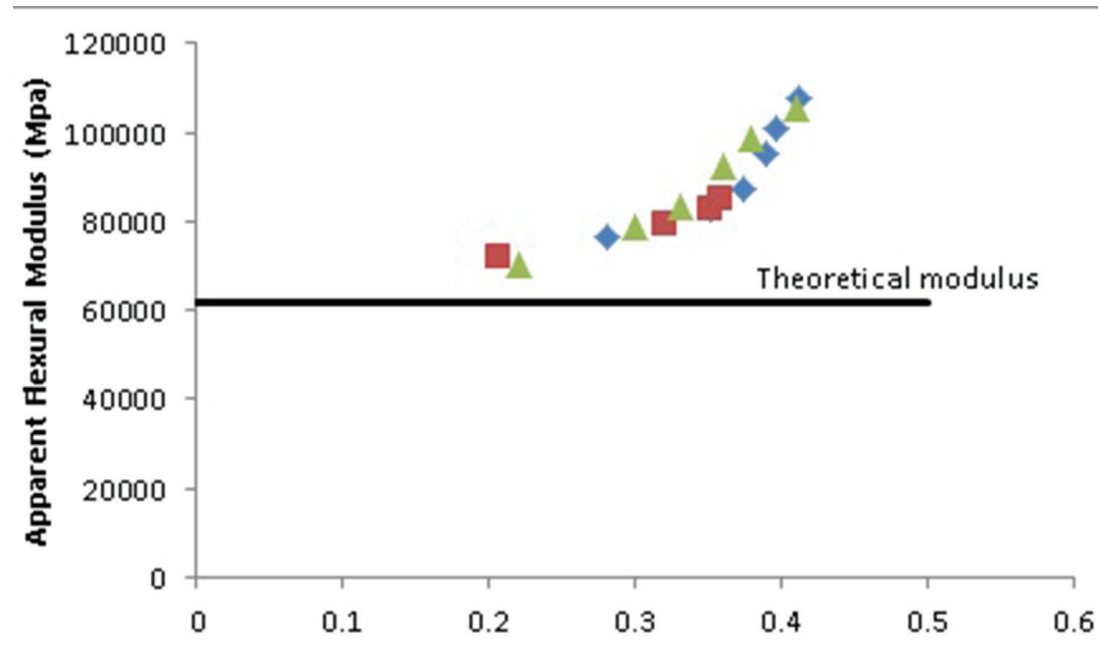

Figure 9: Apparent flexural modulus for the $\left[20_{4} /-20_{4}\right]_{\mathrm{s}}$ layup versus the ratio of the induced twisting moment to the applied bending moment. The blue points represent the width study using a load span of $1 / 2$, the green points represent the width study using a load span of $1 / 3$ and the red points are from the study on the support span. 
$\left[20_{4} /-20_{4}\right]_{s}$ layup, a larger torsional moment results in a larger apparent flexural modulus. The different values of T/M were generated using all the test configurations except for the 16:1 and the 20:1 support spans. All the points lie on one curve which indicates that the apparent flexural modulus is directly dependent on the induced torsion. Reducing the restraint imposed by the fixture brings the apparent flexural modulus closer to the theoretical flexural modulus. The relationship is not linear because the amount of constraint does not depend solely on the total induced torque, but also on how the contact forces are distributed along the length of the rollers.

\section{CONCLUSIONS AND RECOMMENDATIONS}

The theoretical flexural modulus of a composite laminate cannot be calculated using the fourpoint bending set-up and the equations outlined in the ASTM and ISO test standards [1-3]. This calculation produces a measure of the flexibility of the coupon in conjunction with the restraint provided by the test fixture and is highly dependent on the test-up. The less the test fixture constrains the coupon, the closer the apparent flexural modulus will be to the theoretical value. This will occur with narrower coupons with a longer support span. It was shown that the apparent stiffness is directly related to the magnitude of the twisting moment introduced into the coupon by the test fixture. If the magnitude of the twisting moments could be predicted, then the relative increase in the apparent modulus should also be able to be predicted. This leads to the possibility of being able to determine the theoretical flexural modulus of composite laminates using a traditional four-point bend set-up.

\section{REFERENCES}

[1] ASTM D6272-10: Standard Test Method for Flexural Properties of Unreinforced and Reinforced Plastics and Electrical Insulating Materials by Four-Point Bending, 2010.

[2] ASTM D7264/D7264M-07: Standard Test Method for Flexural Properties of Polymer Matrix Composite Materials, 2007.

[3] ISO 14125:1998: Fibre-reinforced plastic composites, determination of flexural properties, 1998.

[4] Whitney, J.M. \& Dauksys, R.J., Flexure experiments on off-axis composites. Journal of Composite Materials, 4, pp. 135-137, 1969. https://doi.org/10.1177/002199837000400115

[5] Whitney, J.M., Browning, C.E. \& Mair, A., Analysis of the flexure test for laminate composite materials. ASTM STP 546, pp. 30-45, 1974.

[6] Lopez-Anido, R., Davalos, J.F. \& Barbero, E.J., Experimental evaluation of stiffness of laminated composite beam elements under flexure. Journal of Reinforced Plastics and Composites, 14, pp. 349-361, 1995. https://doi.org/10.1177/073168449501400403

[7] Grédiac, M., Four-point bending tests on off-axis composites. Composite Structures, 24, pp. 89-98, 1993. https://doi.org/10.1016/0263-8223(93)90030-t

[8] De Baere, I., Van Paepegem, W. \& Degrieck, J., Comparison of different setups for fatigue testing of thin composite laminates in bending. International Journal of Fatigue, 31, pp. 1095-1101, 2009. https://doi.org/10.1016/j.ijfatigue.2008.05.011

[9] El Mahi, A. \& Bezazi, A., Describing the flexural behaviour of cross-ply laminates under cyclic fatigue. Applied Composite Materials, 16, pp. 33-53, 2009. https://doi.org/10.1007/s10443-008-9076-0 
[10] Jalali, S.J. \& Taheri, F., A new test method for measuring the longitudinal and shear moduli of fiber reinforced composites. Journal of Composite Materials, 33(23), pp. 2134-2160, 1999.

https://doi.org/10.1177/002199839903302301

[11] Vargas, G. \& Mujika, F., Determination of in-plane shear strength of unidirectional composite materials using the off-axis three-point flexure and off-axis tensile tests. Journal of Composite Materials, 44(21), pp. 2487-2507, 2010. https://doi.org/10.1177/0021998310369601

[12] Vargas, G. \& Mujika, F., Determination of in-plane shear properties by three-point flexure test of $\pm 45^{\circ}$ anti-symmetric laminates. Polymer Testing, 30, pp. 204-215, 2011. https://doi.org/10.1016/j.polymertesting.2010.11.008

[13] Mujika, F. \& Mondragon, I., On the displacement field for unidirectional off-axis composites in 3-point flexure - part 1: analytical approach. Journal of Composite Materials, 37(12), pp. 1041-1066, 2003. https://doi.org/10.1177/0021998303037012001

[14] Mujika, F., De Benito, A. \& Mondragon, I., On the displacement field for unidirectional off-axis composites in 3-point flexure - Part II: numerical and experimental results. Journal of Composite Materials, 37(13), pp. 1191-1217, 2003. https://doi.org/10.1177/0021998303037013004

[15] Mujika, F., A novel approach for the three-point flexure test of multidirectional laminates. Journal of Composite Materials, 46(3), pp. 259-274, 2011. https://doi.org/10.1177/0021998311412636

[16] Romera, J.M., Adarrage, I., Cantera, M.A. \& Mujika, F., Numerical analysis of displacement and stress fields of off-axis composites in three-point flexure. Journal of Composite Materials, 45(6), pp. 671-682, 2010. https://doi.org/10.1177/0021998310377937

[17] Van Paepegem, W., De Geyter, K., Vanhooymissen, P. \& Degrieck, J., Effect of friction on the hysteresis loops from three-point bending fatigue tests of fibre-reinforced composites. Composite Structures, 72, pp. 212-217, 2006. https://doi.org/10.1016/j.compstruct.2004.11.006

[18] De Baere, I., Van Paepegem, W. \& Degrieck, J., Comparison of different setups for fatigue testing of thin composite laminates in bending. International Journal of Fatigue, 31, pp. 1095-1101, 2009. https://doi.org/10.1016/j.ijfatigue.2008.05.011 